\title{
THREE-DIMENSIONAL MEASUREMENT OF SPRING-BACK CHARACTERISTICS FOR HELICAL PLASTIC HOSES USING COMPUTER VISION
}

\author{
ANH-TUAN DO ${ }^{1}$, KUO-WEI LEE ${ }^{2}$, WEN-HAO CHANG ${ }^{2}$, RUNG-YE LIN ${ }^{2}$ \& QUANG-CHERNG HSU ${ }^{2}$ \\ ${ }^{1}$ Department of Manufacturing Technology for Mechanical Engineering, Hung Yen University of Technology and \\ Education, Vietnam \\ ${ }^{2}$ Department of Mechanical Engineering, National Kaohsiung University of Applied Sciences, Taiwan
}

\begin{abstract}
Using a plastic water hose not only affects water resources, but also affects people's daily lives. Due to over bending or twisting during service times, plastic hoses tend to fold, buckle, or crack. The new developed spiral plastic hose can overcome the above problems, however, how to evaluate its properties is still an industry need. By using machine vision technology to analyze the spiral plastic hose quality such as the spring-back property is a good methodology which can facilitate the trust relationship between the industries and consumers. Three-dimensional machine vision technologies were used to examine five different kinds of plastic hoses, i.e. type A-E. At first, a testing platform is designed and the measuring algorithm is proposed to measure the inner radius of the bent plastic hose. By using image processing technology and the developmental program, the radius information of plastic hoses before and after spring-back are obtained for further analysis. According to experimental results based on the proposed inspection system, Type $B$ plastic hoses behave with no-kink and its spring-back ratio is 3.457, which is the best of the plastic hoses. Plastic hose of Type D behaves kink situation and its spring-back ratio is 1.117 which is the worst. By comparing the experimental results to the manufacturers offering information, a good agreement is obtained. Therefore, this study provides an innovative inspection system to determine plastic hose quality.
\end{abstract}

Keywords: machine vision, spring-back, plastic hose, non-kink.

\section{INTRODUCTION}

The products with convenience operation and energy saving are the mainstream in the market. One of these products, plastic water hose not only affects water resources, but also affects our daily life. Due to over bending or twisting during service times, plastic hose tents to fold, buckle, or crack. Users will doubt about the elastic properties of plastic hoses, and this will affect their willingness to use this kind of product. In addition to fabricate a good product, new design concept and quality uniformity are important. By using machine vision technology to analyze the spiral plastic hose quality such as spring-back property is a good methodology which can facilitate the industries and consumers to trust each other. It also can provide consumers a fair certification in purchasing goods.

At present, due to the rapid development of industrial technology, many detection instruments use machine vision to provide a medium which can detect the object on the computer screen. Through the image processing system, the tasks such as detection, identification, measurement can be performed [1]. The current specification for plastic hose inspection can be found in JIS K 6330-9-2003 [2] which provides the bending test and the bulging test for plastic hose. The other tests mostly are related to surface defect detection such as crack or rupture [3]-[7]. No further specification exists for detecting non-kink behavior or spring-back phenomenon. For the current product quality inspection or inprocess measurement, machine vision technologies have been developed to replace visual 
inspection. By the way, a repeated and tedious work can be done by a machine which can reduce inspection errors and provide a more reliable product quality evaluation system.

In this study, machine vision system is developed to create a new detection method for the spring-back phenomenon of plastic hose. A test platform, including backlight, twocameras and computer codes of image processing and measurement was developed by the authors [8]. In order to create the real situation for using plastic hose, two testing height planes and six fixed positions were designed. For non-kink property test, both ends of plastic hose are held one end of which is fixed and the other end is moved until bouncing or folding situation occurs. For spring-back phenomenon test, both ends of plastic hose are held among which one end is fixed at the zero point and the other end is moved to the pre-set six positions coming from three fixed positions for two testing height planes. After that, the plastic hose is released. Then the spring-back parameter can be calculated based on the radius of plastic hose after release and before release. Image processing technology such as edge detections [9], [10] were used to calculate radius of plastic hose.

By using image processing technology and the development program, the radius information of plastic hose before and after spring-back are obtained for further analysis. By comparing the experimental results to the manufacturer provided information, good agreement is obtained. Therefore, this study provides an innovative inspection system to determine plastic hose quality.

\section{THE PROPOSED MEASUREMENT ARCHITECTURE}

Based on the JIS specification [1], the ways to reach the limit of bending and the maximum durable internal pressure of the plastic pipe/hose have been described. However, the springback characteristics for helical plastic hoses cannot be obtained from this specification. The authors propose the architecture of the proposed three-dimensional measurement of spring back characteristics for helical plastic hoses including CCD camera, zoom lens, image capture card, backlight, light-diffusing plate and platform for holding plastic hose, as shown in Fig. 1.

The platform is designed to adjust the six different positions at two different heights - A and B planes, as shown in Fig. 2. The A plane is set at the origin by the $y$-axis, and the $\mathrm{x}$-axis coordinates are set at three coordinates at $0 \mathrm{~cm}, 15 \mathrm{~cm}$ and $30 \mathrm{~cm}$, respectively. The B plane is raised by $10 \mathrm{~cm}$ from the $\mathrm{y}$-axis coordinate, and the $\mathrm{x}$-axis coordinates are set at three coordinates at $0 \mathrm{~cm}, 15 \mathrm{~cm}$ and $30 \mathrm{~cm}$, respectively. Through the six different positioning points to fix the plastic pipe, the variation of the inner contour radius before and after springback will be recorded. Fig. 3 depicts the test specimens being fixed at one end at the original position, and the other ends at the predefined six positions.

In this study, we use machine vision to establish the detection system of plastic hose spring-back performance. The elasticity of each type of plastic hose is analyzed by measuring the radius data of the inside contour of the hose before and after spring-back. Fig. 4 depicts the flow chart of the proposed system. First, it is necessary to select specimen for inspection. Second, the one end of testing specimen should be fixed in original point while the other end is tightened at one of the predefined six different positions. For the measurement by image processing, it is necessary take one snap image of specimen and conduct analysis. The following step will be releasing the fixed end to let plastic hose spring-back, capture image and conduct analysis. Then precede the above processes again. 


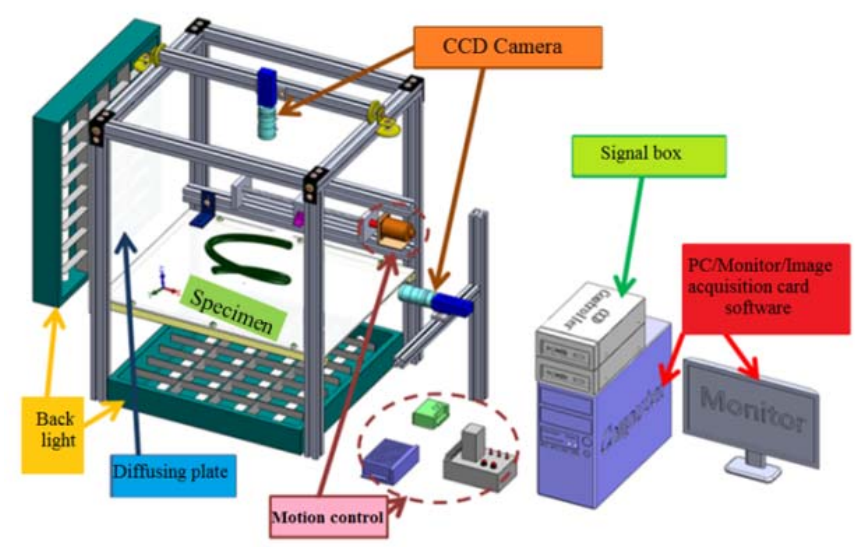

Figure 1: The proposed three-dimensional measurement of spring back characteristics for helical plastic hoses.

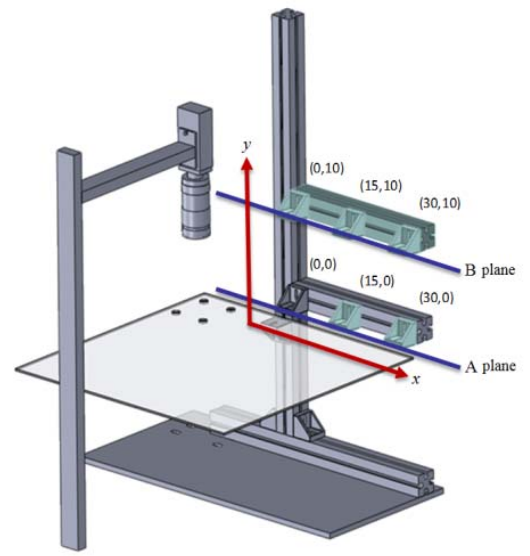

Figure 2: The designed platform to adjust the three different positions at two different heights $-\mathrm{A}$ and $\mathrm{B}$ planes [8].
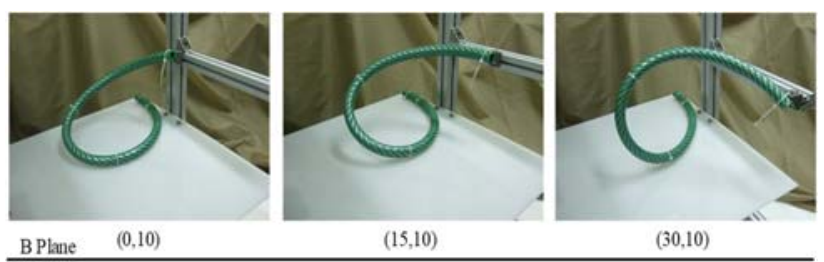

$(15,10)$

$(30,10)$
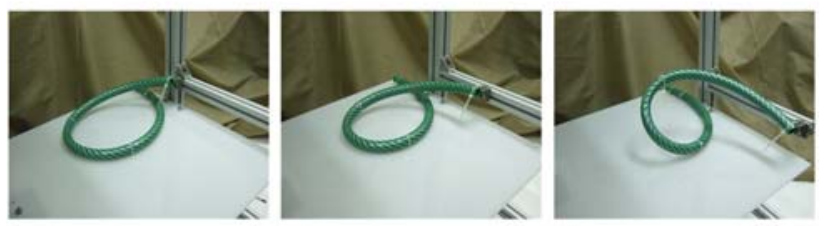

APlane

$(15,0)$

$(30,0)$

Figure 3: The test specimens being fixed in testing platform. 


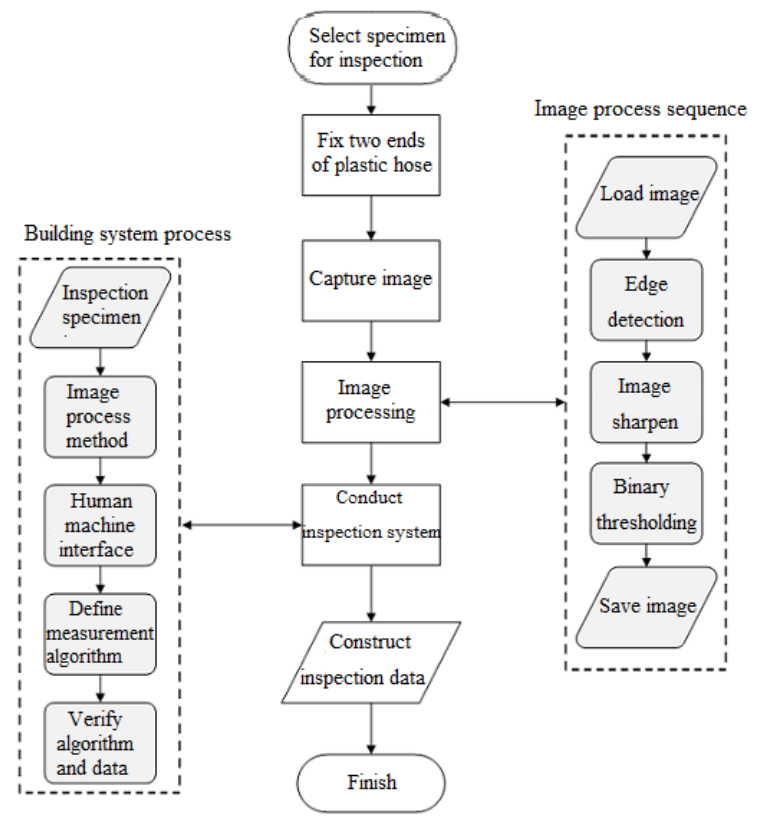

Figure 4: The flow chart of the proposed system.

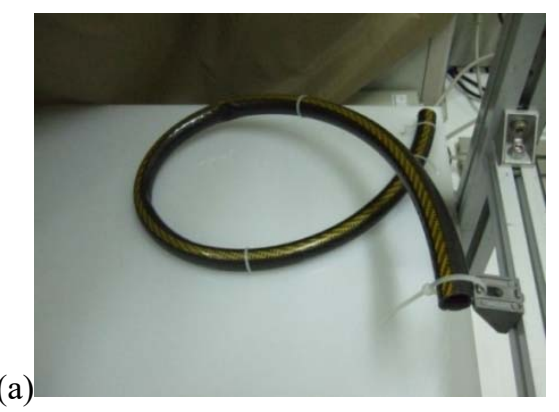

(b)

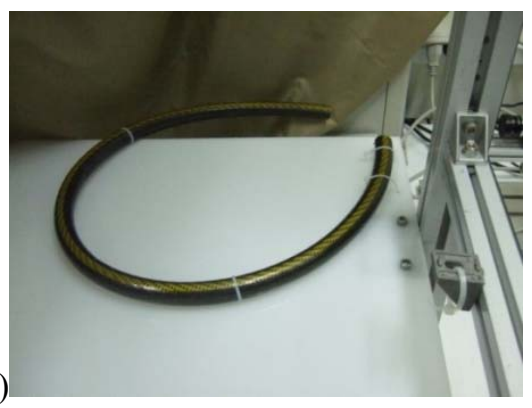

Figure 5: The test specimens being fixed in a testing platform to measure their inner radius. (a) Before spring-back; (b) After spring-back.

\section{THE METHODOLOGY FOR MEASUREMENT}

\subsection{Tests of elastic performance for plastic spiral hose}

There are two important effects needed to measure. The first measurement is about the inner radius of plastic hose before and after spring-back, as shown in Fig. 5, which is called springback test. The elastic performance of the plastic spiral hose can be calculated as the inner radius after spring-back divided by the inner radius before spring-back which can be defined as a spring-back ratio. The larger of the spring-back ratio means the good of the elastic performance of spiral hose. 
The second measurement is about the motion distance when the plastic hose tend to standup without folding, as shown in Fig. 6, which is called pulling test. The elastic performance of the plastic spiral hose can be defined as the horizontal distance between two fixed ends of plastic hose. The larger of the distance, meaning the good of the elastic performance of spiral hose. If the plastic hose can be pulled to a long distance without folding phenomenon occurring which means it can be continuously pulled to become totally straight. Fig. 7 depicts the folding phenomenon for one kind of plastic hose. In order to obtain the motion distance when the plastic hose trying to stand-up, one of its fixed end can be mounted on a ball screw motion device, as shown in Fig. 8.

(a)

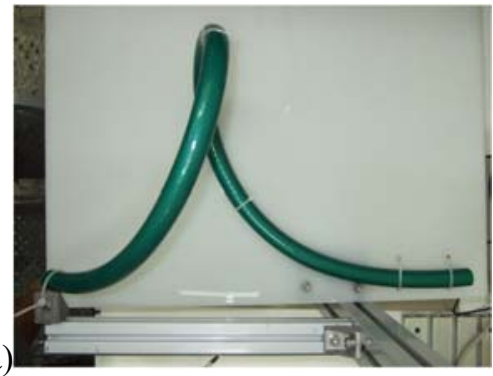

(b)

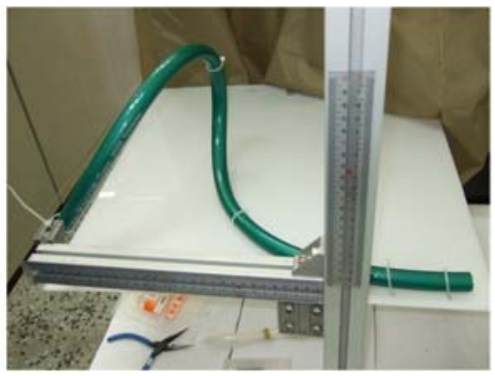

Figure 6: The test specimens being fixed in a testing platform to measure the horizontal distance between two fixed ends of plastic hose without folding. (a) Top view; (b) Side view.

(a)

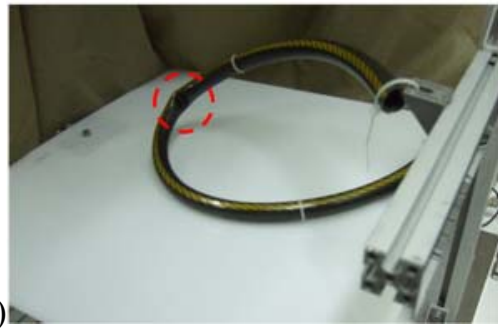

(b)

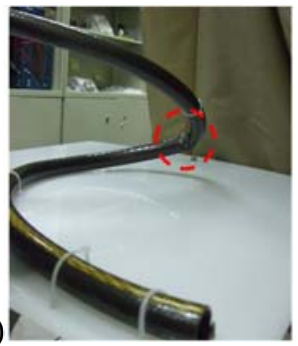

Figure 7: The folding phenomenon occurring for one kind of plastic hose during pulling test. (a) Front view; (b) Side view.

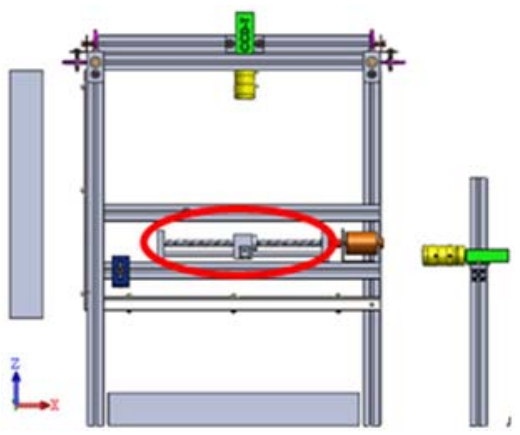

Figure 8: The ball screw motion device to conduct automatic pulling test. 


\subsection{Image processing and measurement}

The detection platform was built by using machine vision technology to evaluate the springback performance of plastic hose. The image size is $640 \times 480$ pixels with 256 grey levels. A micro 10 times zoom lens was mounted on the CCD camera. A man-machine interface was designed to facilitate the operation of the detection system and image processing. Then, the image processing methods were established to measure contours. The developed algorithms can be used to quantify the test data and to obtain the measured data. The Atos system with a raster projection device and the Poly-Works measurement software were used to test the experimental samples to verify the proposed algorithms and the measured data. In this study, the contour of the inner side of the plastic hose is the objective to be measured. The backlight is selected so that the background is white and the object to be tested is black. Fig. 9 shows the acquired image and the edge detection image from top view.

Three represented points $\left(p x_{1}, p y_{1}\right),\left(p x_{2}, p y_{2}\right),\left(p x_{3}, p y_{3}\right)$ can be found by using line searching at three predefined searching lines where have intersection points with the inner contour, as shown in Figs 9 and 10. Based on three points consist in one circle, the coordinate of its center point can be represented as shown in eqns (1) and (2). Then, the radius of this circle $(R)$ can be obtained, as shown in Fig. 11. The above method to obtain radius of this circle is only valid when the real plane is parallel to the projection plane as shown in Fig. 12(a). If the real plane is inclined to the projection plane, as shown in Fig. 12(b), then the radius should be modified based on the height information of these three points. The modified radius $\left(R^{\prime}\right)$ is calculated by using eqn (3).
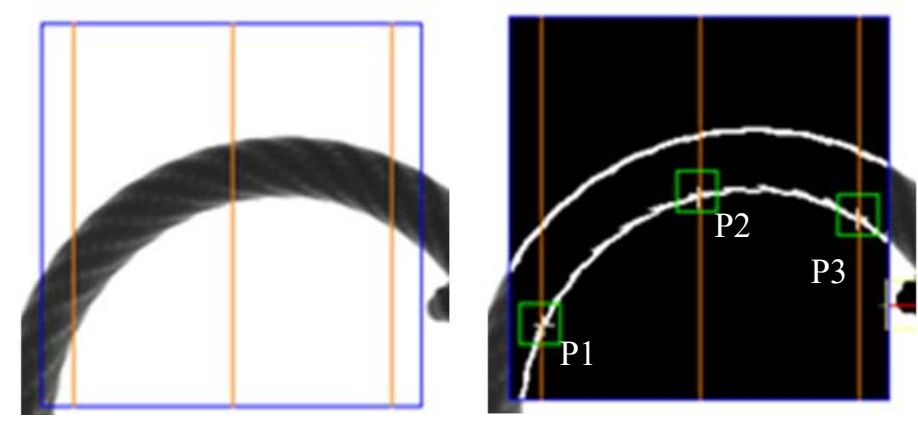

Figure 9: The acquired image (left) and the edge detection image (right) of plastic hose from top view.

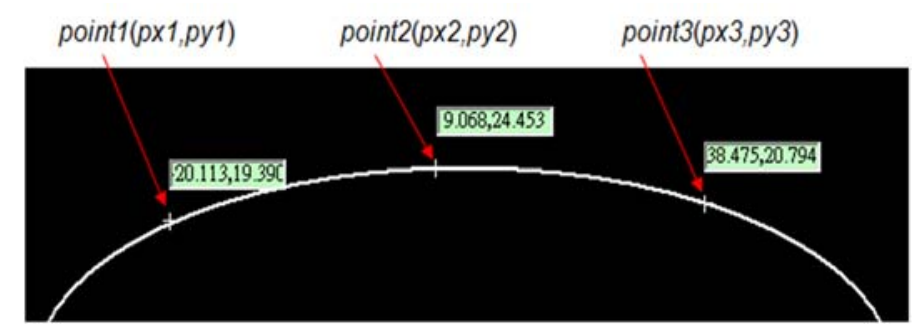

Figure 10: Three represented points at three predefined searches lines having intersection with the inner contour. 


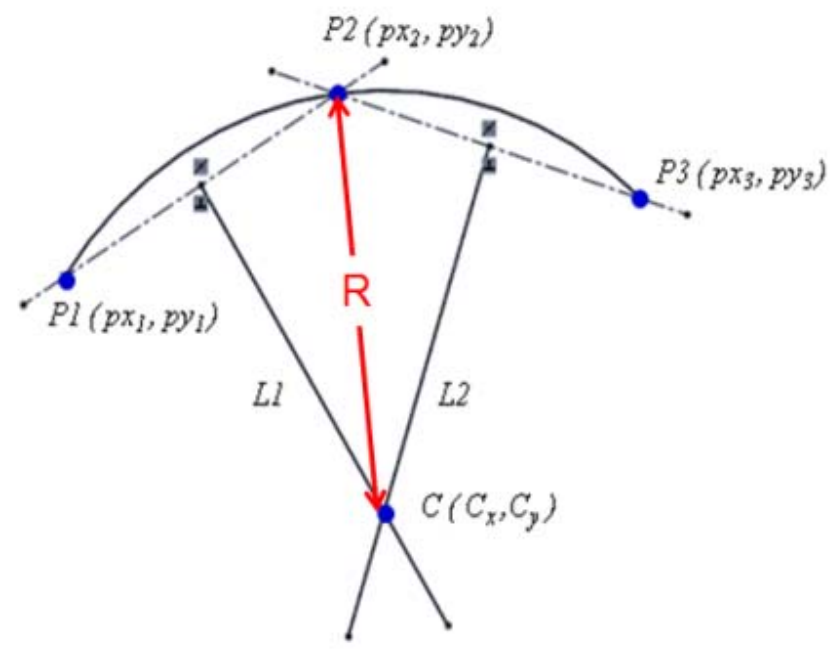

Figure 11: Three points consist in one circle.

Plastic hose parallel to its projection plane

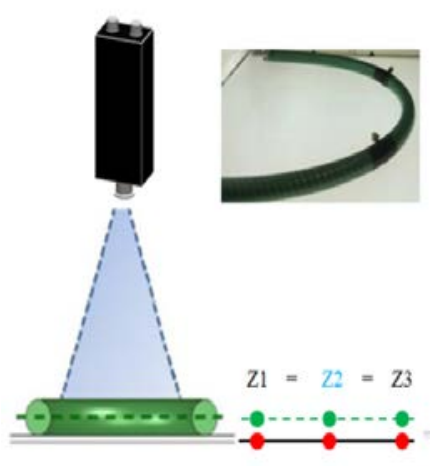

(a) - Projection plane -..-- Ture plane
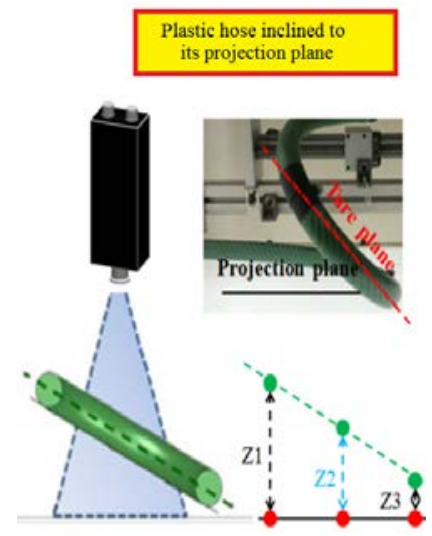

(b) - True point $\bullet$ Measurement point

Figure 12: Depictions of two plastic hose measurement. (a) Projection plane is parallel to true plane; (b) Projection plane is inclined to real plane.

$$
\begin{gathered}
C_{x}=\left\{\left(p y_{1}-p y_{2}\right) \times\left[\left(p x_{1}^{2}+p y_{1}^{2}-p x_{3}^{2}-p y_{3}^{2}\right)\right] / 2-\right. \\
\left.\left(p y_{1}-p y_{3}\right) \times\left[\left(p x_{1}^{2}+p y_{1}^{2}-p x_{2}^{2}-p y_{2}^{2}\right)\right] / 2\right\} / \\
{\left[\left(p x_{1}-p x_{3}\right) \times\left(p y_{1}-p y_{2}\right)-\left(p x_{1}-p x_{2}\right) \times\left(p y_{1}-p y_{3}\right)\right]} \\
C_{y}=\left\{\left(p x_{1}-p x_{3}\right) \times\left[\left(p x_{1}^{2}+p y_{1}^{2}-p x_{2}^{2}-p y_{2}^{2}\right)\right] / 2-\right. \\
\left.\left(p x_{1}-p x_{2}\right) \times\left[\left(p x_{1}^{2}+p y_{1}^{2}-p x_{3}^{2}-p y_{3}^{2}\right)\right] / 2\right\} / \\
{\left[\left(p x_{1}-p x_{3}\right) \times\left(p y_{1}-p y_{2}\right)-\left(p x_{1}-p x_{2}\right) \times\left(p y_{1}-p y_{3}\right)\right]} \\
R^{\prime}=\sqrt{R^{2}+(\Delta Z)^{2}}
\end{gathered}
$$


where $\Delta \mathrm{Z}=(Z 1-Z 3) / 2, Z 1$ and $Z 3$ are the heights of two reference points, $R$ is radius of circle in projection plane, and $R^{\prime}$ is the modified radius of circle in true plane.

\section{RESULTS AND DISCUSSION}

\subsection{System verification}

In order to determine the accuracy, the proposed method for plastic hose radius, the Atos, 3D non-contact coordinate measurement machine, was used to obtain the triangular grid data and point clouds data of the plastic hose at a certain location, as shown in Fig. 13. Fig. 14 depicts the sequence of Atos measurement: (a) plastic hose with anti-reflective paint and marks; (b) point clouds; (c) surface model; (d) inner radius measurement.

Repeated measurements for this test were conducted; the measurement results for inner radius of plastic hose are $105.85 \mathrm{~mm} \sim 106.19 \mathrm{~mm}$ from the proposed system and 105.945 $\mathrm{mm} \sim 106.053 \mathrm{~mm}$ from the Atos and Poly-Works. By comparing measurement results of these two methods, although the tolerance of the proposed system is larger than the Atos and Poly-Works, the range of the former cover the latter which proves the reliability of the proposed system.

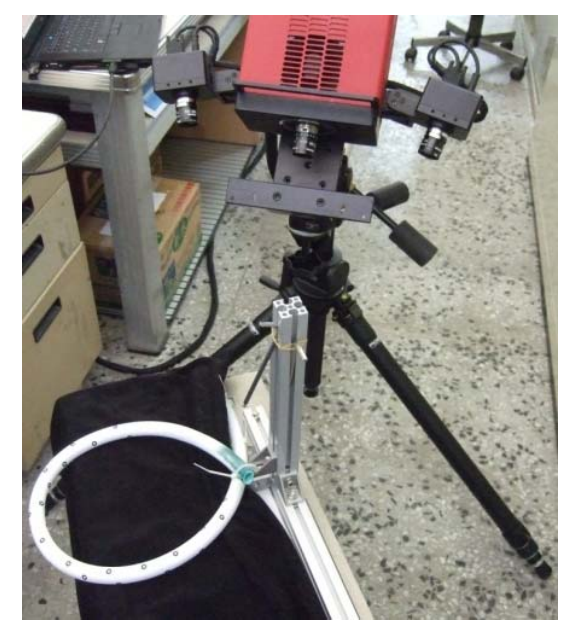

Figure 13: 3D measurement for verification by using Atos system.

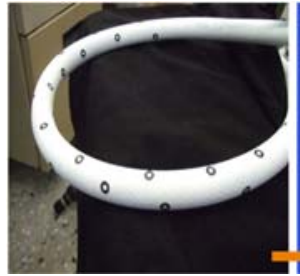

(a)

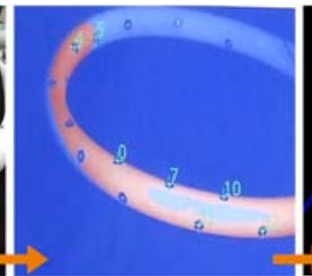

(b)

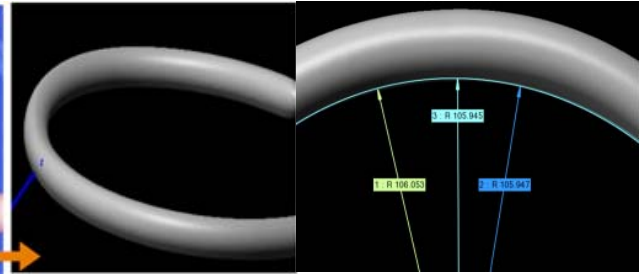

(c) (d)

Figure 14: Verification sequence. (a) Plastic hose with anti-reflective paint and marks; (b) Point clouds; (c) Surface model; (d) Inner radius measurement. 
4.2 Comparison of measurement radius of plastic tube before and after spring-back

Five types of plastic hoses were tested by using the proposed platform and measurement algorithms at six different positioning points (three positioning points for every two planes). Fig. 3 depicts Type A of plastic hose at six different positioning points before spring-back. Fig. 15 depicts these five types (Type A-E) of plastic hoses at the same positioning point (30, 10). There are three situations occurred during testing: folding, as shown in Fig. 15 Type D; bouncing-off, as shown in Fig. 15 Type A - C and E; only bending, as shown in Fig. 3. In the above five types, the elastic property of Type $\mathrm{D}$ is worse than the other types.

For the testing plastic hose without folding and bouncing-off, the inner radius before and after spring-back were measured as described in Section 3.1 and 3.2. Fig. 16 shows the inner radius for Type A and B before and after spring-back at three positioning points. One can find that for both hoses when being moved to the right positioning points the inner radius become smaller but after spring-back it becomes larger which means the more elastic energy is stored when inner radius is smaller.

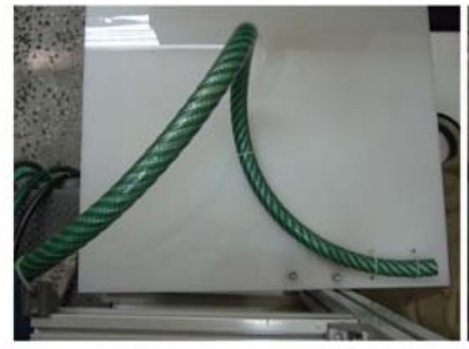

Type A

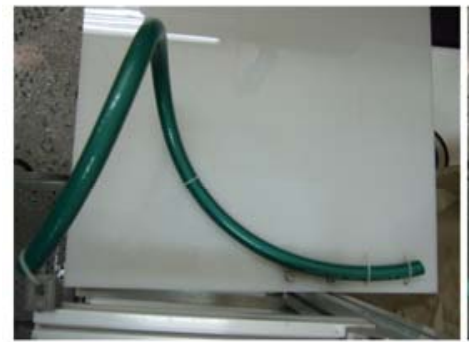

Type C

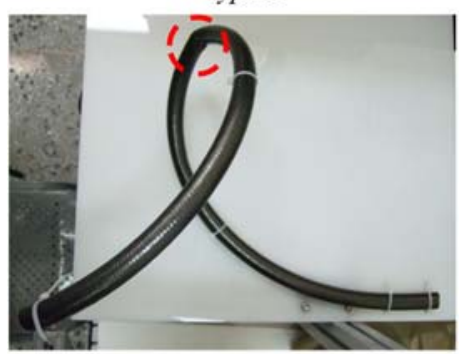

Type D

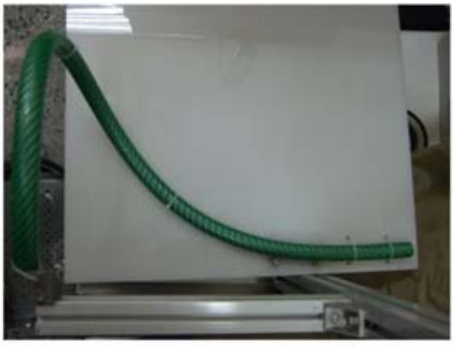

Type B

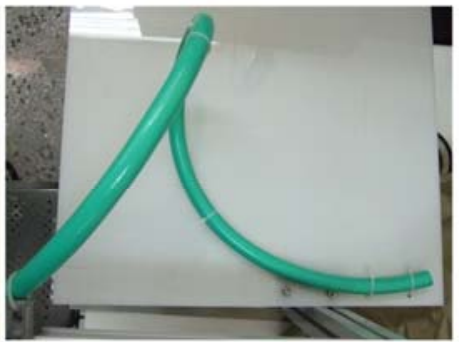

Type E

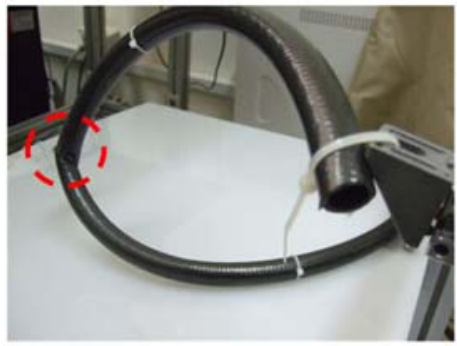

Figure 15: Five types $(\mathrm{A} \sim \mathrm{E})$ of plastic hoses at the same positioning point $(30,10)$; Type D folds; other Types bounce-off. 


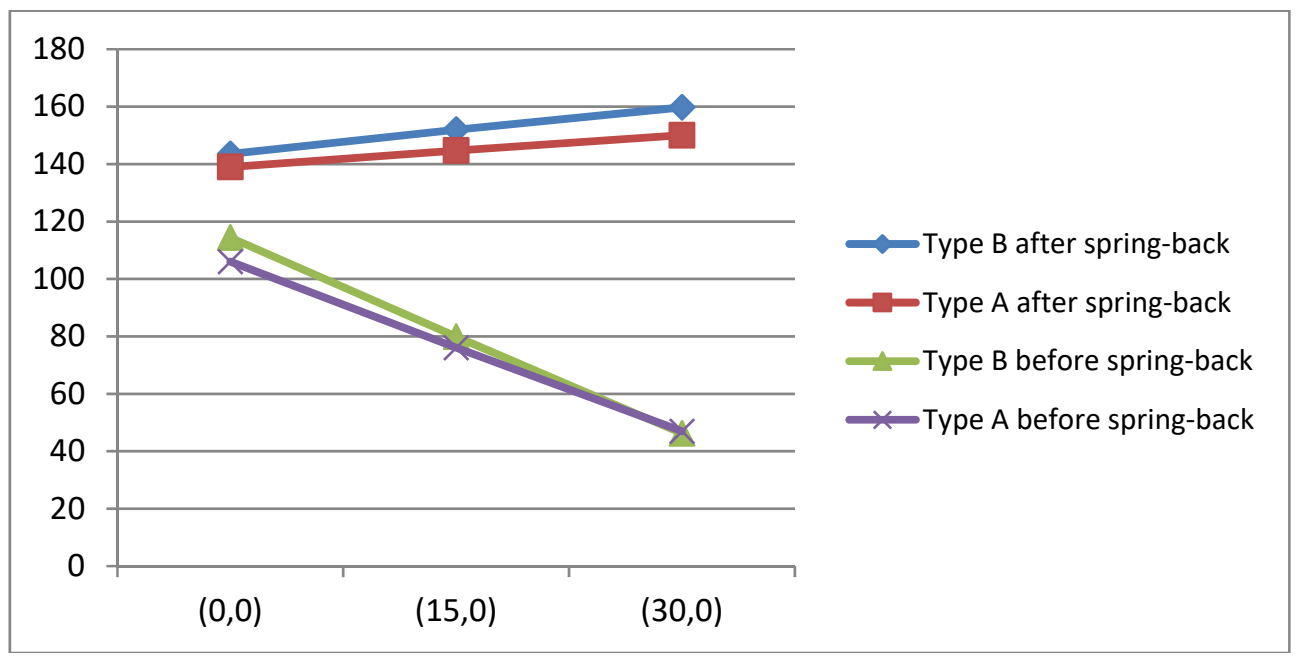

Figure 16: The inner radius of Type $\mathrm{A}$ and $\mathrm{B}$ at three positioning points before and after spring-back.

Table 1-5 list the inner radius for five plastic hoses before and after spring-back by using the proposed measurement platform and algorithm. Table 6 lists the testing results for these five types of plastic hoses including bouncing-off, folding, and spring-back ratio. The springback ratio was calculated by dividing inner radius after spring-back by inner radius before spring-back. One can easily describe the elastic property for these five plastic hoses from Table 6. Type B has earlier bouncing off situation means this hose elastic property is best. Type $\mathrm{D}$ has folding situation means this hose elastic property is worse. By comparing the spring-back ratios for Type A, C, and E, the elastic property of Type A is better than the others.

Table 1: Inner radius measurement for Type A before and after spring-back.

\begin{tabular}{|c|c|c|c|c|c|}
\hline $\begin{array}{c}\text { Positioning } \\
\text { points }\end{array}$ & $\begin{array}{c}\text { Before } \\
\text { spring-back }\end{array}$ & $\begin{array}{c}\text { After } \\
\text { spring-back }\end{array}$ & $\begin{array}{c}\text { Positioning } \\
\text { points }\end{array}$ & $\begin{array}{c}\text { Before } \\
\text { spring-back }\end{array}$ & $\begin{array}{c}\text { After } \\
\text { spring-back }\end{array}$ \\
\hline $\mathbf{( 0 , 0 )}$ & $106.3_{-0.5}^{+0.3}$ & $139.0_{-0.9}^{+0.9}$ & $(0,10)$ & $111.7_{-0.2}^{+0.2}$ & $139.7_{-0.4}^{+0.7}$ \\
\hline $\mathbf{( 1 5 , 0 )}$ & $76.1_{-0.5}^{+0.4}$ & $144.7_{-0.3}^{+0.4}$ & $(15,10)$ & $40.5_{-0.1}^{+0.4}$ & $145.7_{-0.3}^{+0.3}$ \\
\hline $\mathbf{( 3 0 , 0 )}$ & $47.0_{-0.2}^{+0.2}$ & $150.1_{-0.5}^{+0.2}$ & $(30,10)$ & \multicolumn{2}{|c|}{ Bouncing-off } \\
\hline
\end{tabular}

Unit: $\mathrm{mm}$.

Table 2: Inner radius measurement for Type B before and after spring-back.

\begin{tabular}{|c|c|c|c|c|c|}
\hline $\begin{array}{c}\text { Positioning } \\
\text { points }\end{array}$ & $\begin{array}{c}\text { Before } \\
\text { spring-back }\end{array}$ & $\begin{array}{c}\text { After } \\
\text { spring-back }\end{array}$ & $\begin{array}{c}\text { Positioning } \\
\text { points }\end{array}$ & $\begin{array}{c}\text { Before } \\
\text { spring-back }\end{array}$ & $\begin{array}{c}\text { After } \\
\text { spring-back }\end{array}$ \\
\hline $\mathbf{( 0 , 0 )}$ & $111.4_{-0.2}^{+0.5}$ & $143.5_{-0.5}^{+0.5}$ & $(0,10)$ & $122.6_{-0.1}^{+0.1}$ & $155.6_{-0.3}^{+0.3}$ \\
\hline $\mathbf{( 1 5 , 0 )}$ & $79.9_{-0.2}^{+0.5}$ & $152.0_{-0.9}^{+0.8}$ & $(15,10)$ & \multicolumn{2}{|c|}{ Bouncing-off } \\
\hline $\mathbf{( 3 0 , 0 )}$ & $46.2_{-0.3}^{+0.4}$ & $159.7_{-0.7}^{+0.5}$ & $(30,10)$ & \multicolumn{2}{|c|}{ Bouncing-off } \\
\hline
\end{tabular}

Unit: $\mathrm{mm}$. 
Table 3: Inner radius measurement for Type $\mathrm{C}$ before and after spring-back.

\begin{tabular}{|c|c|c|c|c|c|}
\hline $\begin{array}{c}\text { Positioning } \\
\text { points }\end{array}$ & $\begin{array}{c}\text { Before } \\
\text { spring- } \\
\text { back }\end{array}$ & $\begin{array}{c}\text { After } \\
\text { spring- } \\
\text { back }\end{array}$ & $\begin{array}{c}\text { Positioning } \\
\text { points }\end{array}$ & $\begin{array}{c}\text { Before } \\
\text { spring- } \\
\text { back }\end{array}$ & $\begin{array}{c}\text { After } \\
\text { spring- } \\
\text { back }\end{array}$ \\
\hline $\mathbf{( 0 , 0 )}$ & $86.6_{-0.5}^{+0.4}$ & $120.6_{-0.6}^{+0.6}$ & $(0,10)$ & $88.7_{-0.2}^{+0.2}$ & $130.8_{-0.3}^{+0.2}$ \\
\hline$(\mathbf{1 5 , 0 )}$ & $68.0_{-0.3}^{+0.1}$ & $121.3_{-0.8}^{+0.7}$ & $(15,10)$ & $73.5_{-0.1}^{+0.4}$ & $130.7_{-0.2}^{+0.2}$ \\
\hline $\mathbf{( 3 0 , 0 )}$ & $38.0_{-0.1}^{+0.1}$ & $121.2_{-0.4}^{+0.4}$ & $(30,10)$ & \multicolumn{2}{|c|}{ Bouncing-off } \\
\hline
\end{tabular}

Unit: $\mathrm{mm}$.

Table 4: Inner radius measurement for Type D before and after spring-back.

\begin{tabular}{|c|c|c|c|c|c|}
\hline $\begin{array}{c}\text { Positioning } \\
\text { points }\end{array}$ & $\begin{array}{c}\text { Before } \\
\text { spring- } \\
\text { back }\end{array}$ & $\begin{array}{c}\text { After } \\
\text { spring- } \\
\text { back }\end{array}$ & $\begin{array}{c}\text { Positioning } \\
\text { points }\end{array}$ & $\begin{array}{c}\text { Before } \\
\text { spring- } \\
\text { back }\end{array}$ & $\begin{array}{c}\text { After } \\
\text { spring- } \\
\text { back }\end{array}$ \\
\hline $\mathbf{( 0 , 0 )}$ & $105.1_{-0.8}^{+0.8}$ & $117.4_{-0.3}^{+0.3}$ & $(0,10)$ & $103.1_{-0.5}^{+0.3}$ & $117.2_{-0.2}^{+0.2}$ \\
\hline $\mathbf{( 1 5 , 0 )}$ & $86.6_{-0.5}^{+0.4}$ & $117.4_{-0.3}^{+0.3}$ & $(15,10)$ & $84.8_{-0.5}^{+1.0}$ & $119.2_{-0.1}^{+0.1}$ \\
\hline $\mathbf{( 3 0 , 0 )}$ & \multicolumn{2}{|c|}{ Folding } & $(30,10)$ & \multicolumn{2}{c|}{ Folding } \\
\hline
\end{tabular}

Unit: $\mathrm{mm}$.

Table 5: Inner radius measurement for Type E before and after spring-back.

\begin{tabular}{|c|c|c|c|c|c|}
\hline $\begin{array}{c}\text { Positioning } \\
\text { points }\end{array}$ & $\begin{array}{c}\text { Before } \\
\text { spring- } \\
\text { back }\end{array}$ & $\begin{array}{c}\text { After } \\
\text { spring- } \\
\text { back }\end{array}$ & $\begin{array}{c}\text { Positioning } \\
\text { points }\end{array}$ & $\begin{array}{c}\text { Before } \\
\text { spring- } \\
\text { back }\end{array}$ & $\begin{array}{c}\text { After } \\
\text { spring- } \\
\text { back }\end{array}$ \\
\hline $\mathbf{( 0 , 0 )}$ & $98.9_{-0.5}^{+0.6}$ & $137.6_{-0.3}^{+0.5}$ & $(0,10)$ & $100.2_{-1.2}^{+0.7}$ & $140.4_{-0.3}^{+0.5}$ \\
\hline$(\mathbf{1 5 , 0 )}$ & $76.8_{-0.3}^{+0.2}$ & $139.4_{-0.3}^{+0.3}$ & $(15,10)$ & $80.6_{-0.4}^{+0.6}$ & $140.3_{-0.2}^{+0.2}$ \\
\hline $\mathbf{( 3 0 , 0 )}$ & $50.1_{-0.2}^{+0.2}$ & $139.4_{-0.3}^{+0.9}$ & $(30,10)$ & \multicolumn{2}{|c|}{ Bouncing-off } \\
\hline
\end{tabular}

Unit: $\mathrm{mm}$.

Table 6: The spring-back ratios for Type A-E of plastic hoses.

\begin{tabular}{|c|c|c|c|c|c|c|}
\hline \multicolumn{2}{|c|}{$\begin{array}{l}\text { Plastic hoses } \\
\text { Position- } \\
\text { ing points }\end{array}$} & Type A & Type B & Type C & Type D & Type E \\
\hline \multirow{3}{*}{$\begin{array}{c}\text { A } \\
\text { plane }\end{array}$} & $(0,0)$ & 1.311 & 1.288 & 1.394 & 1.117 & 1.392 \\
\hline & $(15,0)$ & 1.903 & 1.902 & 1.784 & 1.355 & 1.815 \\
\hline & $(30,0)$ & 3.196 & 3.457 & 3.189 & Folding & 2.783 \\
\hline \multirow{3}{*}{$\begin{array}{c}\text { B } \\
\text { plane }\end{array}$} & $(0,10)$ & 1.251 & 1.269 & 1.475 & 1.138 & 1.401 \\
\hline & $(15,10)$ & 3.593 & $\begin{array}{c}\text { Bouncing- } \\
\text { off }\end{array}$ & 1.777 & 1.405 & 1.741 \\
\hline & $(30,10)$ & $\begin{array}{c}\text { Bouncing- } \\
\text { off }\end{array}$ & $\begin{array}{c}\text { Bouncing- } \\
\text { off }\end{array}$ & $\begin{array}{l}\text { Bouncing- } \\
\text { off }\end{array}$ & Folding & $\begin{array}{c}\text { Bouncing- } \\
\text { off }\end{array}$ \\
\hline
\end{tabular}




\section{CONCLUSIONS}

There are several important issues related to the performance of plastic hose such pipe thickness, diameter, the number of yarn selection, yarn weaving, spiral strips adding, etc. All of these will affect elastic properties of plastic hose. Especially for non-kink hose, how to evaluate its performance is still under developed. In the proposed paper, a new testing method including platform and algorithms is developed which can verify the quality of plastic hose beside bulging test.

The results of the comprehensive experiments show that the data obtained by the detection system are consistent with the information provided by the collaborating company, and their quality trend are the same as the experimental data of the manufacturer. Therefore, according to the research results, it can provide a good system for testing the spring-back performance of non-kink plastic hose.

\section{ACKNOWLEDGEMENT}

The authors thank Toford Plastic Manufacturing Corporation, Taiwan, for providing financial support and testing specimens.

\section{REFERENCES}

[1] Gonzalez, R.C. \& Woods, R.E., (eds), Digital Image Processing, Pearson Prentice Hall: New Jersey, pp. 1-30, 2007.

[2] Japanese Industrial Standards Committee, Testing methods for rubber and plastics hoses - Part 9: Bending properties of hoses and tubing, JIS K 6330-9, 2003.

[3] Satoshi, A., Inspection method of winding Pitch of wire of rubber hose and inspection device for the same. Japan Paten. Publication number 2006-258439.

[4] Satoshi, A., Method and device for visual inspection of rubber hose. Japan Paten. Publication number 2006-250798.

[5] Tulcan, A., Tulcan, L., Stan, D. \& Iclanzan, T., Three-dimensional inspection of injected plastic parts. Materiale Plastice, 44(4), pp. 316-320, 2007.

[6] Hiroyuki, U. \& Tetsuji, N., Visual examination system of rubber hose. Japan Paten. Publication number 2008-026254.

[7] Takehiro, I. \& Ken, T., Hose visual recognition holder and beer server including the same. Japan Paten. Publication number 2012-224385.

[8] Hsu, Q.C. \& Lee, K.W., Inspection device and method for spring-back performance of plastic hose. Taiwan Paten, I453387, 2014.

[9] Canny, J., A computational approach to edge detection. IEEE Transactions on Pattern Analysis and Machine Intelligence, 8(6), pp. 679-698, 1986.

[10] Lu, S., Wang, Z. \& Shen, J., Neuro-fuzzy synergism to the intelligent system for edge detection and enhancement. Pattern Recognition, 36, pp. 2395-2409, 2003. 